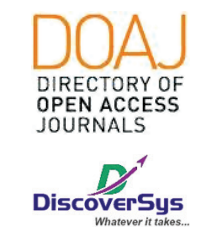

Published by DiscoverSys

\section{Kehamilan usia dini di wilayah kerja UPT Kesmas Tegalalang I Kabupaten Gianyar, Bali-Indonesia}

\author{
Raka Mery Hardiani, ${ }^{1}$ Daondy Friarsa, ${ }^{1}$ Aswin Panji, ${ }^{1}$ Luh Seri Ani ${ }^{2 *}$
}

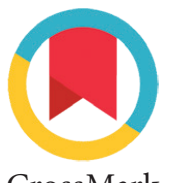

CrossMark

\section{ABSTRACT}

Introduction: Early pregnancy events are predicted to increase globally by 2030. Early pregnancy is a global problem that occurs in countries with high, middle, and low economic status. Pregnant women aged 1019 years are at high risk of eclampsia, puerperal endomtritis and systemic infections. This study aims to determine the description of early pregnancy at the UPT of the Primary Health Care Center Tegallalang I Gianyar-Bali. Methods: Descriptive research using cross-sectional design was carried out on 22 pregnant women in the Primary Health Care Center Tegallalang I Gianyar, Bali. The sample was selected using the total sampling method. Data collection was conducted in May 2018. Early pregnancy data along with respondent characteristics were collected by interview method. Early pregnancy is determined based on the age of adolescents when $<20$ years pregnant. Data were analyzed descriptively to obtain proportions and trends in the incidence of early pregnancy.

Results: The prevalence of pregnancy at an early age was $13.6 \%$. Early pregnancy is more prevalent in mothers who do not work (22.2\%) and education levels are low (25\%). All pregnant women early in the second trimester of pregnancy (100\%), have performed ANC services and consume blood boosting tablets (Fe). In this study it was also found that one person had not received Tetanus Toksoid (TT) immunization, was in an abnormal BMI and blood pressure. There are no early pregnant women who have anemia.

Conclusion: The prevalence of early pregnancy is relatively high, so primary and secondary prevention efforts need to be intensified to reduce the incidence of early pregnancy and its negative effects.

Keywords: early pregnancy, anemia, tetanus toxoid, ANC

Cite This Article: Hardiani, R.M., Friarsa, D., Panji, A., Ani, L.S. 2019. Kehamilan usia dini di wilayah kerja UPT Kesmas Tegalalang I Kabupaten Gianyar, Bali-Indonesia. Intisari Sains Medis 10(2): 375-379. D0I: 10.15562/ism.v10i2.418

\title{
ABSTRAK
}

Latar Belakang: Kejadian kehamilan usia dini diprediksi akan meningkat secara global pada tahun 2030. Kehamilan usia dini merupakan masalah global yang terjadi di negara dengan status ekonomi tinggi, menengah dan rendah. Ibu hamil dengan usia 10 19 tahun berisiko tinggi mengalami eklamsi, endomtritis puerperal dan infeksi sistemik. Penelitian ini bertujuan untuk mengetahui gambaran kehamilan usia dini di UPT Kesmas Tegallalang I Gianyar-Bali.

Metode: Penelitian desktriptif dengan menggunakan rancangan potong lintang dilakukan terhadap 22 ibu hamil di wilayah UPT Kesmas Tegallalang I Gianyar Bali. Sampel dipilih dengan menggunakan metode total sampling. Pengumpulan data dilakukan pada bulan Mei 2018. Data kehamilan usia dini beserta karakteristik responden dikumpulkan dengan metode wawancara. Kehamilan usia dini ditentukan berdasarkan usia remaja pada saat hamil $<20$ tahun. Data dianalisis secara deskriptif untuk mendapatkan proporsi dan trend kejadian kehamilan usia dini.

Hasil: Prevalensi kehamilan usia dini dijumpai sebesar 13,6\%. Kehamilan usia dini lebih banyak ditemukan pada ibu yang tidak bekerja $(22,2 \%)$ dan tingkat pendidikan rendah $(25 \%)$. Seluruh ibu hamil usia dini berada pada trimester kedua kehamilan (100\%), sudah melakukan pelayanan ANC dan mengonsumsi tablet penambah darah (Fe). Dalam penelitian ini juga ditemukan ada satu orang belum mendapatkan imunisasi Tetanus Toksoid (TT), berada dalam IMT dan tekanan darah yang tidak normal. Tidak ada ibu hamil usia dini yang dijumpai mengalami anemia.

Simpulan: Prevalensi kehamilan usia dini relatif tinggi, sehingga upaya pencegahan primer dan skunder perlu di intensifkan untuk menurunkan kejadian kehamilan usia dini berserta dampaknegatifnya.
Masyarakat dan Kedokteran Pencegahan Fakultas Kedokteran, Universitas Udayana

\section{*Corresponding to:}

Luh Seri Ani, Departemen Kesehatan Masyarakat dan Kedokteran Pencegahan Fakultas Kedokteran, Universitas Udayana seriani@unud.ac.id

Kata kunci: kehamilan usia dini, anemia, tetanus toksoid, asuhan antenatal.

Cite Pasal Ini: Hardiani, R.M., Friarsa, D., Panji, A., Ani, L.S. 2019. Kehamilan usia dini di wilayah kerja UPT Kesmas Tegalalang I Kabupaten Gianyar, Bali-Indonesia. Intisari Sains Medis 10(2): 375-379. D0I: 10.15562/ism.v10i2.418

\section{PENDAHULUAN}

Setiap tahun, diduga sebanyak 21 juta remaja usia 15-19 tahun dan sebanyak 2 juta remaja putri usia di bawah 15 tahun mengalami kehamilan di negara sedang berkembang. ${ }^{1}$ Sekitar 16 juta remaja putri usia 15-19 tahun dan 2,5 juta remaja putri usia di bawah 16 tahun dijumpai melahirkan di 
negara sedang berkembang. ${ }^{1}$ Di Indonesia, angka kehamilan remaja dilaporkan sebesar $1,9 \%$ pada tahun 2017 dimana kejadian kehamilan usia dini lebih banyak dijumpai di daerah pedesaan $(2,71 \%)$ dibandingkan dengan daerah perkotaan $(1,28 \%){ }^{2}$

Beberapa penelitian menunjukan bahwa kehamilan pada usia dini menimbulkan komplikasi kehamilan seperti preeklamsi, abortus, partus lama, bayi lahir prematur, pendarahan, cacat kongenital, berat bayi lahir rendah, fistula vesikovaginal dan retro vaginal, serta kanker serviks. ${ }^{3}$ Kematian maternal pada wanita hamil dan melahirkan pada usia di bawah 20 tahun dilaporkan berrisiko sebesar 2-5 kali lebih tinggi dari pada kematian maternal pada usia 20 sampai 29 tahun dan meningkat kembali pada usia 30- 35 tahun. ${ }^{4}$ WHO melaporkan kematian bayi dan neonates sebesar 50\% lebih tinggi pada ibu di bawah umur 20 tahun dibandingkan pada ibu yang berumur 20-29 tahun. ${ }^{1}$

Penelitian tentang kehamilan usia dini telah banyak dilakukan baik di Dunia dan di Indonesia, namun masih dijumpai adanya variasi dalam besarnya kejadian kehamilan usia dini serta trend kehamilan usia dini..$^{5-7}$ Berdasarkan hal tersebut maka penelitian ini bertujuan untuk mengetahui besarnya kejadian beserta trend kehamilan usia dini berradsarkan karakteristik ibu hamil.

\section{METODE}

Studi deskriptif potong lintang dilakukan terhadap 22 ibu hamil di wilayah kerja UPT Kesmas Telalalang Gianyar Bali yang dipilih dengan metode total sampling. Kriteria inklusi dalam penelitian ini adalah ibu hamil yang berdomisili di wilayah Puskesmas Tegallalang I serta bersedia berpartisipasi dalam penelitian ini. Kriteria eksklusi adalah ibu hamil dengan kehamilan patologis. Besar sampel dihitung dengan penggunakan nilai $\alpha=0,05$ dan nilai $d=0,1$. Data penelitian dikumpulkan pada bulan Mei 2018. Data kehamilan usia dini, pendidikan, pekerjaan, perilaku ante natal care (ANC), imunisasi tetanus toksoid (TT), dan konsumsi tablet tambah darah dikumpulkan dengan metode wawancara sedangkan data lingkar lengan atas (LILA), tinggi badan, berat badan, indeks masa tubuh (IMT), usia kandungan, kadar $\mathrm{Hb}$, tekanan darah di ukur dengan metode observasi. Kadar $\mathrm{Hb}$ diukur dengan alat $\mathrm{Hb}$ test (Easy Touch HB test), IMT di ukur dengan membandingkan berat badan dan tinggi badan ibu hamil, tekanan darah diukur dengan menggunakan alat tensi meter yang sudah dikalibrasi. Kehamilan usia dini ditentukan berdasarkan usia ibu pada saat hamil $<20$ tahun. Data dianalisis secara deskriptif untuk mengukur besar beserta trend kejadian kehamilan usia dini.

\section{HASIL}

Pada tabel 1 dijumpai sebagian besar responden memiliki tingkat pendidikan sedang, status bekerja, status non KEK, IMT normal, usia kehamilan trimester III, tempat ANC di Klinik Swasta, sudah mendapatkan imunisasi TT, mendapatkan tablet

Tabel 1 Distribusi Frekuensi Karakteristik Responden

\begin{tabular}{lcc}
\hline Variabel & $\begin{array}{c}\text { Frekuensi } \\
(\mathrm{n})\end{array}$ & $\begin{array}{c}\text { Proporsi } \\
(\%)\end{array}$ \\
\hline
\end{tabular}

Tingkat Pendidikan

$\begin{array}{ccc}\text { Tinggi } & 2 & 9,1 \\ \text { Sedang } & 16 & 72,7 \\ \text { Rendah } & 4 & 18,2 \\ \text { Pekerjaan } & & \\ \text { Bekerja } & 13 & 59,1 \\ \text { Tidak Bekerja } & 9 & 40,9\end{array}$

\section{Status KEK}

KEK

Non KEK

IMT

Kurus

Normal

Berat Badan Lebih

Obesitas

Umur Kehamilan

Trimester I

22,7

Trimester II

36,4

Trimester III

40,9

Tempat ANC

Puskesmas

Bidan

77,3

Dokter

13,6

63,6

Imunisasi Toksoid

Ya

81,8

Tidak

Konsumsi Pil Penambah

Darah

$$
\text { Ya }
$$

20

90,9

Tidak

2

9,1

Paritas

0

1

2

40,9

40,9

Status Anemia

$\mathrm{Ya}$

4,5

Tidak 
Tabel 2 Proporsi kejadian kehamilan usia dini

\begin{tabular}{lcc}
\hline Kehamilan usia dini & Frekuensi & Persen \\
\hline Ya & 3 & 13,6 \\
Tidak & 19 & 86,4 \\
\hline
\end{tabular}

Tabel 3 Cross tabulasi kejadian kehamilan usia dini berdasarkan karakteristik ibu hamil

\begin{tabular}{|c|c|c|c|c|c|}
\hline \multirow[b]{3}{*}{ Variabel } & & \multicolumn{4}{|c|}{ Kehamilan usia dini } \\
\hline & & \multicolumn{2}{|c|}{$\mathrm{Ya}(13,6 \%)$} & \multicolumn{2}{|c|}{ Tidak $(86,4 \%)$} \\
\hline & & $\mathbf{n}$ & $\%$ & $\mathbf{n}$ & $\%$ \\
\hline \multirow[t]{3}{*}{ Pendidikan } & Tinggi & 0 & 0 & 2 & 100,0 \\
\hline & Sedang & 2 & 12,5 & 14 & 87,5 \\
\hline & Rendah & 1 & 25,0 & 3 & 75,5 \\
\hline \multirow[t]{2}{*}{ Pekerjaan } & Bekerja & 1 & 7,1 & 13 & 92.9 \\
\hline & Tidk bekerja & 2 & 22,2 & 9 & 77,8 \\
\hline \multirow[t]{3}{*}{ Usia kehamilan } & Trimester I & 0 & 0 & 6 & 100 \\
\hline & Trimester II & 3 & 42,9 & 4 & 57,1 \\
\hline & Trimester III & 0 & 0 & 10 & 100 \\
\hline \multirow[t]{2}{*}{ Konsumsi TTD } & $\mathrm{Ya}$ & 3 & 14,3 & 18 & 85,7 \\
\hline & Tidak & 0 & 0 & 2 & 100 \\
\hline \multirow[t]{2}{*}{ Imunisasi $\mathrm{TT}$} & Ya & 2 & 10,5 & 17 & 89,5 \\
\hline & Tidak & 1 & 25,0 & 3 & 75,0 \\
\hline \multirow[t]{2}{*}{ Status KEK } & Ya & 0 & 0 & 1 & 100 \\
\hline & Tidak & 3 & 13,6 & 19 & 86,4 \\
\hline \multirow[t]{2}{*}{ IMT } & Normal & 2 & 20,0 & 8 & 80,0 \\
\hline & Tidak normal & 1 & 7,7 & 12 & 92,3 \\
\hline \multirow[t]{2}{*}{ Anemia } & Ya & 0 & 0 & 1 & 100 \\
\hline & Tidak & 3 & 15,8 & 19 & 84,2 \\
\hline \multirow[t]{2}{*}{ Tekanan darah } & Normal & 2 & 11,1 & 18 & 88,9 \\
\hline & Tidak normal & 1 & 25.5 & 4 & 75,0 \\
\hline
\end{tabular}

tambah darah dan status tidak anemia. Tabel 2 menunjukan kejadian kehamilan usia dini sebesar $13,6 \%$.

Pada tabel 3 dijumpai kehamilan usia dini cendrung lebih banyak dijumpai pada ibu hamil dengan pendidikan rendah, tidak bekerja, usia kehamilan trimester II, konsumsi TTD, tidak Imunisasi TT, status non KEK, IMT normal, tidak anemia dan tekanan darah tidak normal.

\section{PEMBAHASAN}

Kehamilan usia dini dalam penelitian ini dijumpai sebesar $13,6 \%$. Proporsi kehamilan usia dini pada penelitian ini dijumpai sedikit lebih tinggi dibandingkan dengan proporsi kehamilan usia dini di Manado pada tahun 2015 yaitu sebesar 12,54\%, ${ }^{7,8}$ Angka kehamilan usia dini pada penelitian ini dan di Manado jauh lebih tinggi jika dibandingkan dengan hasil Riset Kesehatan Dasar (Riskesdas) 2013 yaitu sebesar 1,97\%. ${ }^{8,9}$ Akan tetapi jika dibandingkan dengan kejadian kehamilan usia dini diberbagai negara seperti Baltimore sebesar $52,9 \%$, Johannesburg sebesar $28,8 \%$, Ibadan sebesar $24,1 \%$, Shanghai sebesar 16,1 dan New Delhi sebesar 52,2\% maka angka kejadian kehamilan usia dini pada penelitian ini jauh lebih kecil. ${ }^{5,6}$

Perbedaan ini dimungkinkan oleh karena perbedaan jumlah sampel dimana penelitian yang dilakukan di Afrika menggunakan $>10$ ribu partisipan, penelitian di lima kota lainnya menggunakan rata-rata 200 partisipan. Sedangkan pada penelitian ini hanya menggunakan 20 ibu hamil. $^{7}$

Pada penelitian ini dijumpai bahwa kehamilan usia dini cendrung lebih banyak pada ibu hamil dengan pendidikan rendah, tidak bekerja, usia kehamilan pada trimester II, mengkonsumsi TTD, tidak Imunisasi TT, status non KEK, IMT normal, tidak anemia dan tekanan darah tidak normal. Hasil ini didukung oleh hasil penelitian yang dilakukan di Sub-Saharan Africa yang mendapatkan bahwa faktor determinan kehamilan usia dini adalah faktor sosial budaya, ekonomi, individual dan pelayanan kesehatan. ${ }^{6}$ Penelitian sebelumnya mendapatkan faktor kemiskinan, tradisi, alkohol dan obat-obatan, kurangnya pendidikan kesehatan seksual, serta pergaulan bebas merupakan faktor-faktor yang paling berpengaruh. ${ }^{10}$

Sebesar 25\% ibu hamil usia dini dijumpai memiliki tingkat pendidikan sedang dan sebesar 12,5\% dengan tingkat pendidikan rendah. Hasil penelitian ini dijumpai berbeda dengan hasil penelitian yang dilakukan di Puskesmas Remaja Samarinda pada tahun 2011 dimana ibu hamil usia dini dengan berpendidikan sedang dijumpai sebesar 23,3\% dan ibu hamil usia dini dengan pendidikan rendah sebesar 76,7\%. ${ }^{12}$ Selain itu berdasarkan data SDKI 2012 dijumpai adanya penurunan angka fertilitas secara umum seiring dengan meningkatnya tingkat pendidikan wanita. Angka Fertilitas Total (TFR) wanita dengan pendidikan perguruan tinggi adalah 2,4 anak sedangkan TFR wanita yang tidak tamat SD adalah 3,0 anak. Perbedaan proporsi tingkat pendidikan ibu hamil usia dini tersebut dimungkinkan oleh karena kehamilan usia dini tidak hanya dipengaruhi oleh tingkat pendidikan namun juga dipengaruhi oleh faktor-faktor lain.

Pada penelitian ini juga mendapatkan bahwa proporsi ibu hamil usia dini lebih banyak dijumpai pada ibu yang tidak bekerja (66,7\%). Dari pemeriksaan kehamilan beberapa karakteristik kehamilan usia dini lain juga dijumpai dalam penelitian ini yaitu pemberian tablet tambah darah, imunisasi tetanus toksoid, tinggi badan, berat badan, status 
gizi, tekanan darah dan kadar Hb. Berdasarkan hasil penelitian didapatkan bahwa semua ibu hamil usia dini sudah mendapatkan tablet penambah darah. Berdasarkan hasil SDKI 2012, hanya sebanyak $67.7 \%$ wanita hamil usia 15-19 tahun mendapatkan tablet penambah darah. ${ }^{4}$ Kementrian Kesehatan merekomendasikan bahwa ibu hamil diberikan tablet besi minimal 1 tablet/hari saat malam selama 90 hari sejak awal kehamilan. Dengan demikian, pemberian tablet tambah darah perlu ditingkatkan pada ibu hamil khususnya pada ibu wamil di usia dini. Dalam pemberian tablet tambah darah juga perlu dievaluasi kepatuhan ibu hamil mengkonsumsi tablet besi untuk menurunkan kejadian anemia pada ibu hamil, meskipun dalam penelitian ini tidak ditemukan ibu hamil dengan status anemia positif.

Penelitian ini menjumpai proporsi ibu hamil usia dini yang belum mendapatkan imunisasi TT yaitu sebesar 33,3\%. Data SDKI tahun 2012 melaporkan sebanyak $45,3 \%$ ibu hamil usia dini sudah menerima 2 atau lebih imunisasi TT selama kehamilan terakhir. ${ }^{4}$ Perbedaan angka ini dimungkinkan oleh karena usia kehamilan ibu hamil beragam dari trimester I-III. Kementrian Kesehatan juga menganjurkan agar ibu mendapat dua kali imunisasi tetanus toksoid (TT) selama kehamilan. TT 1 dapat diberikan sejak diketahui positif hamil dimana biasanya diberikan pada kunjungan pertama ibu hamil ke pelayanan kesehatan dan TT 2 dapat diberikan 1 bulan setelah TT 1 dengan lama perlindungan 3 tahun. ${ }^{12,16}$

Rerata kadar $\mathrm{Hb}$ ibu hamil usia dini pada penelitian ini dijumpai sebesar $11,5 \mathrm{gr} / \mathrm{dL}$ dan sebesar 5\% ibu hamil dijumpai anemia. Angka ini lebih kecil jika dibandingkan dengan kejadian anemia pada ibu hamil di wilayah Puskesmas Bahu Manado yang mendapatkan kejadian anemia sebesar $32,5 \% .^{13}$ Kejadian anemia pada penelitian ini juga lebih rendah dari angka nasional yaitu $37,1 \%{ }^{9}$ dan $48,9 \%$ pada tahun $2018 .{ }^{14}$ Perbedaan ini dimungkinkan oleh karena waktu dan metode pemeriksaan kadar hb pada ibu hamil. Pada penelitian ini, pemeriksaan kadar hb dilakukan pada saat hamil, baik pada trimester I atau II atau III dan alat yang digunakan adalah Sahli dimana metode ini memiliki sensitifitas dan spesifitas yang relatif lebih rendah dibanding dengan metode lainnya.

Sebanyak 4,5\% ibu hamil usia dini dijumpai memiliki tekanan darah tidal normal. Angka ini lebih kecil jika dibandingkan dengan angka nasional yaitu sebesar $12,7 \%{ }^{15}$ Hipertensi dapat terjadi sebelum kehamilan dan saat kehamilan. Kejadian hipertensi pada kehamilan sekitar 5-15\%, dan merupakan satu dari 3 penyebab mortalitas dan morbiditas ibu bersalin di samping infeksi dan perdarahan.

\section{SIMPULAN}

Prevalensi kehamilan usia dini dijumpai sebesar $13,6 \%$. Kehamilan usia dini lebih banyak ditemukan pada ibu yang tidak bekerja, tingkat pendidikan rendah (25\%). Seluruh ibu hamil usia dini berada pada trimester kedua kehamilan, sudah melakukan pelayanan ANC dan mengonsumsi tablet penambah darah (Fe). Dalam penelitian ini juga ditemukan ada satu orang belum mendapatkan imunisasi Tetanus Toksoid (TT), berada dalam IMT dan tekanan darah yang tidak normal. Tidak ada ibu hamil usia dini yang dijumpai mengalami anemia.

\section{KONFLIK KEPENTINGAN}

Penulis menyatakan tidak terdapat suatu konflik kepentingan terhadap publikasi dari artikel ini.

\section{PENDANAAN}

Penelitian ini tidak mendapatkan suatu pendanaan yang diberikan oleh pemerintah ataupun lembaga swasta lainnya.

\section{KONTRIBUSI PENULIS}

Konsep penelitian: Luh Seri, Raka Merry Hardiani. Analisis statistic: Luh Seri Ani, Raka Mery Hardiani. Pengumpulan data dan input data: Raka Mery Hardiani, Daondy Friarsa, Aswin Panji. Penyusunan naskah Penelitian Raka Mery Hardiani, Daondy Friarsa, Aswin Panji, Luh Seri Ani.

\section{DAFTAR PUSTAKA}

1. WHO. Adolescent pregnancy [Internet]: WHO Global Report; 2008 (Disitasi: 21 Februari 2017) Tersedia di: http://www.who.int/news-room/fact-sheets/detail/ adolescent-pregnancy.

2. BKKBN. Survei Demografi dan Kesehatan Indonesia 2017. Jakarta: Laporan BKKBN; 2018.

3. Simarmata O, Sudikno S, Kristina K, Bisara D. Determinan Kejadian Komplikasi Persalinan Di Indonesia: Analisis Data Sekunder Riset Kesehatan Dasar 2010. Jurnal Kesehatan Reproduksi. 2015;5(3):1-5.

4. Badan Pusat Statistik. Survei Demografi dan Kesehatan Indonesia (SDKI)2012. BPS - BKKBN - Depkes - ORC Macro Calverton (USA). Jakarta: SDKI 2012; 2013.

5. Heena B, Anna K, Mark E, Michele D, Adesolu O, Oladosu O, Lou C, Freya S, Robert B, . Prevalence and Determinants of Adolescent Pregnancy in Urban, Disadvantaged Settings across Five Cities. J Adolesc Health. 2014;55(60):S48-S57.

6. Getachew MK, Arowojolu AO, Odukogbe AA, Lemayehu WY. Prevalence and determinants of adolescent pregnancy in Africa: a systematic review and Metaanalysis. Reproductive Health. 2018;15:195-199. 
7. Karlin Abdurradjak, Linda MM, John JE. Karakteristik kehamilan dan persalinan pada usia $<20$ tahun di RSUP Prof. Dr. R. D. Kandou Manado periode 1 Januari 2013 31 Desember 2014. Jurnal e-Clinic (eCl). 2016;4(1):4-8

8. Badan Penelitian dan Pengembangan Kesehatan Kementerian Kesehatan RI. Riset Kesehatan Dasar; RISKESDAS 2013. [Internet]. Riset Kesehatan Dasar Mentri Kesehatan Indonesia (disitasi: 20 Februari 2018). Tersedia di: http://www.depkes.go.id/resources/download/ general/Hasil\%20Riskesdas\%202013.pdf

9. Yakubu I, Salisu WJ. Determinants of adolescent pregnancy in sub-Saharan Africa: a systematic review. Reprod Health. 2018;27;15(1):15-19.

10. Dev RA, Rabi B, Amudha P, Teijlingen V, Glyn C. Factors associated with teenage pregnancy in South Asia: a systematic review. Health Science Journal;2010;4(1):3-14.

11. Faridah Hariyani. Hubungan penegtahuan Ibu hamil tentang Kehamilan Usia Dini dengan Kesehatan reproduksi di Puskesmas Remaja Kota Samarinda. Mahakam Midwifery Journal. 2011;1(1):28 - 37 .

12. Kementerian Kesehatan Republik Indonesia. Buku Kesehatan Ibu dan Anak. Jakarta: Kementerian Kesehatan dan Japan International Cooperation Agency (JICA); 2016.
13. Aprilia. Kadar hemoglobin ibu hamil di Puskesmas Bahu Manado. Bagian Obstetri dan Ginekologi Fakultas Kedokteran Universitas Sam Ratulangi-RSUP Prof.dr.R.D. Kandou Manado; 2016.

14. Kemenkes. Riskesdas 2017 [Internet]. Riset Kesehatan Dasar Kementrian Kesehatan Indonesia [disitasi 21 Februari 2018]. Tersedia di: http://www.depkes.go.id/ resources/download/infoterkini/materi_rakorpop_2018/ Hasil\%20Riskesdas\%202018.pdf

15. Kementerian Kesehatan Republik Indonesia. Pedoman Pelayanan Antenatal. Jakarta: Direktoral Bina Pelayanan Medik Dasar Direktorat Jenderal Bina Pelayanan Medik Departemen Kesehatan RI; 2007.

16. Singh $\mathrm{P}$, Khan $\mathrm{S}$, Mittal R. Anemia during pregnancy in the women of western nepal. Bali Medical Journal. 2013;2(1):14-16.

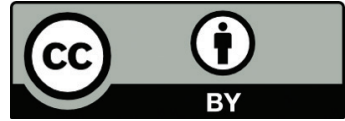

This work is licensed under a Creative Commons Attribution 